\title{
Razón y experiencia: contribuciones para una ampliación de la diversidad epistemológica
}

\author{
Reason and experience: contributions to a broadening \\ of epistemological diversity

\section{Fernando Lautaro Ramírez} \\ Facultad de Filosofía y Letras, Universidad Nacional de Cuyo \\ ffer.rramirez@gmail.com
}

\begin{abstract}
Resumen
La transformación filosófica efectuada por Xavier Zubiri, sobre todo en su obra de madurez: Inteligencia sentiente, permite repensar las bases de una racionalidad en unidad estructural con los sentidos, posibilitando una pluralidad de modos de acceder a la realidad en su fundamento (experiencia), y superar, de esta manera, la racionalidad monológica promovida por el positivismo y el pragmatismo. Para tal fin recorremos los distintos puntos de jalonamiento de su obra: en primer lugar, la aprehensión primordial de realidad desde sus múltiples aperturas sentientes; luego, nos detenemos en la constitución del sentido por el logos haciendo énfasis en el modo en que la cultura prioriza un tipo de sentido (visión, audición, tacto, etc.) por sobre el resto, fraguando un tipo de apertura a la realidad y determinando un horizonte de sentido de la misma; posteriormente, indagamos en el modo en que la razón accede al fundamento de lo real, esto nos permite poner en evidencia cómo las distintas racionalidades justifican sus propias opciones de sentido. A partir de aquí efectuamos la contraposición entre una racionalidad religiosas fundada en criterios científico-históricos y una de tipo religiosa, estrictamente, lo que permite terminar de sistematizar y de dar una unidad de sentido a los planteos previos realizados. En virtud de esto, conseguimos explorar las consecuencias para la sociología del conocimiento (Epistemologías del Sur), como, también, las condiciones de un diálogo intercultural, y, ulteriormente, los escenarios de una construcción interlógica.
\end{abstract}

Palabras clave: inteligencia sentiente, razón, sentidos, realidad, verdad.

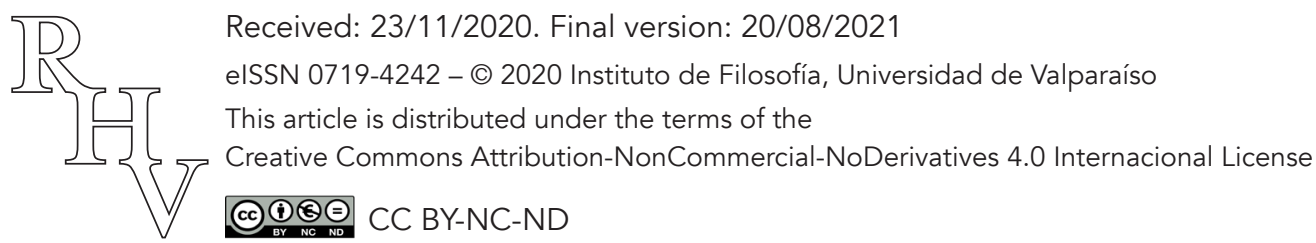


Razón y experiencia: contribuciones para una ampliación de la diversidad epistemológica

Fernando Lautaro Ramírez

\begin{abstract}
The philosophical transformation carried out Xavier Zubiri, especially in his mature work: Sentient intelligence allows to rethink the bases of rationality in structural unity with the senses, allowing a plurality of ways of accessing reality on its foundation (experience), and surpass, in that way, the monological rationality promoted by positivism and pragmatism. To this end, we move through the different landmarks of Zubiri's work: first, the primordial apprehension of reality from its multiple sentient openings; then, we stop at the constitution of meaning by logos emphasizing how culture prioritize one type of sense (view, hear, touch, etc.) over the rest, forging a type of openness to reality and determining a horizon of meaning for it; later, we inquire into how reason accesses the foundation of the real, this allows us to show how the different rationalities settle their options for meaning. From here we contrast with religious rationality founded on historical-scientific criterion, and a strictly religious one, which, ultimately, allow us to finish systematizing and giving a unity of meaning to the previews proposals that were made. Finally, all this enables us to explore the consequences for a sociology of knowledge (Epistemologies of the South), and to think about the conditions of intercultural dialogue, and, subsequently, the scenarios of and interlogical construction.
\end{abstract}

Keywords: sentient intelligence, reason, senses, reality, truth.

\title{
1. Introducción
}

En su cuento El Aleph, Borges narra algo ante lo cual sólo un lector avieso puede permanecer impávido. Allí pretende conjurar en unos renglones, vivaces y hartamente bien escritos, un "objeto secreto y conjetural", el multum in parvo, el infinito Aleph, el "inconcebible universo". En él podemos ver un esfuerzo ingente por traducir en sucesivo, porque el lenguaje lo es, lo que los ojos del protagonista vieron en simultáneo; esto es, la totalidad del universo. El cuento tiene la virtud de narrar fantásticamente lo imposible, la completitud del universo cifrado en un sitio, en el cual convergen todos los puntos del universo (Borges 1974, 617). A renglón seguido el protagonista afirma con voz enaltecida y humillada al mismo tiempo: "Sentí infinita veneración, infinita lástima", hecho que se comprende en estas palabras: "Temí que no quedara una sola cosa capaz de sorprenderme, temí que no me abandonara jamás la impresión de volver. Felizmente, al cabo de unas noches de insomnio, me trabajó otra vez el olvido". (Borges 1974, 626)

El protagonista del cuento nos relata con remordimiento que ha hurtado el saber de los dioses, una sabiduría solo reservada a una mente divina, al Dios creador de la Kabbalah, podemos decir. Este conocimiento es la totalidad del universo, que conlleva una sustracción en el horizonte de cualquier novedad. Incluso lo incierto, lo imprevisible, lo inverosímil, tienen un lugar en esa totalidad. La experiencia ha quedado estragada desde su

Revista de Humanidades de Valparaíso, 2021, No 17, 231-250

(c) $(9)(9)$ CC BY-NC-ND 
Razón y experiencia: contribuciones para una ampliación de la diversidad epistemológica

Fernando Lautaro Ramírez

misma raíz; pues, al ser todo visible queda absorbido en una completa sincronía. Mientras la vivencia que nace de lo otro, de lo allende que es propio de la alteridad, no puede ser concebida, dado que no hay diacronía que logre poner freno a ese poder.

Los avatares del personaje borgiano al ver el Aleph revela subrepticiamente las transformaciones posibles de una racionalidad cuya constitución suprime u oblitera saberes y, por tanto, experiencias, cifrando todo en un lenguaje átono y unívoco, pues, como le ocurre al protagonista que abandona el sótano del Aleph envuelto en indiferencia, encontramos que su silencio es evasivo y displicente, pues teme que ya nada le sorprenda, que no quede más que la impresión de volver siempre a esa única experiencia; pues cada rostro, cada calle, cada casa, no es sino un símbolo de aquello. En efecto, cualquier pretensión racional de suturar el abismo que la separa con la realidad, es decir, de poder apresar en un multum in parvo, al haber hecho de su mapa cognitivo un espejo de la realidad, olvidando así su condición de mapa (Roig 2017), es un peligro epitemológico y una trampa contra la experiencia.

Xavier Zubiri, en este mismo sentido, en su artículo "Nuestra situación intelectual" (1948) plantea varios retos a los intelectuales de la ciencia y la filosofía. Su diagnóstico parte de que hay un estado de confusión en la ciencia. Por un lado, porque no se tiene un objeto propio, no se sabe exactamente de qué trata ella. Luego se observa que no sola hay ausencia de unidad sistemática, sino que, al mismo tiempo, hay una falta de perspectiva. Lo que lleva a una dispersión del saber humano y a una positivización extrema del mismo. Otro aspecto notable que destaca Zubiri es la desorientación en el mundo. Es decir, frente a la proliferación indefinida de verdades positivas circulando, se comienza un proceso de criba del saber bajo la consigna de la utilidad inmediata. Todo lo que no es útil es eliminado como curiosidad. Esto provoca una pérdida de horizonte de los fines.

De aquí parten una serie de riesgos a los que la inteligencia se expone, nosotros reparamos en dos de ellos, por ser nodal para nuestro análisis. El primero es el positivismo. Este tiene que ver con el esfuerzo humano por constituir su mundo. De aquí la ciencia comienza disolviendo el mundo ingenuo para delimitarlo en su justo espacio de análisis cognoscitivo: "los hechos", eso que está ante uno y simplemente lo está. Esto hechos se los suele reducir a meros datos empíricos. De aquí que la verdad científica es nada más que un acuerdo con esos datos, y la ciencia será un saber acerca de su concatenación ordenada. De aquí se deriva la idea de que todos los saberes son equivalentes, y su unidad dispersa sólo se da en la enciclopedia del saber entero.

La prolongación natural del positivismo es, a modo de ver de Zubiri, el pragmatismo. En la ciencia hay una situación interna: la de definir la verdad necesariamente. Esta necesidad -responde a la índole misma de la vida biológica — hace que la ciencia reduzca la variedad enorme de los datos sensibles a unas pocas relaciones sencillas que admiten

Revista de Humanidades de Valparaíso, 2021, No 17, 231-250

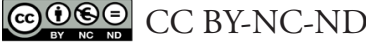


Razón y experiencia: contribuciones para una ampliación de la diversidad epistemológica

Fernando Lautaro Ramírez

prever el curso de los fenómenos. La definición de leyes que permitan dominar el curso de las cosas futuras, que permitan manejarlas, reduciendo la ciencia a mera eficacia; de aquí el pragmatismo.

Esta caracterización zubiriana de la situación del saber occidental a mediados del siglo pasado es sintomática del lugar en que queda el vínculo entre razón (experiencia) y realidad, donde observa que prima la simplificación y reducción del saber, con el consiguiente peligro derivado de un multum in parvo borgeano. ${ }^{1}$ En este sentido, para cambiar la forma de razón que preside el conocimiento y su estructura le es necesario a nuestro autor mostrar de qué manera se accede a lo real, en otras palabras, cómo constituimos cualquier "pretensión de verdad"2 - el acceso a lo real desde una lengua, cultura, u horizonte ontológico - que, ulteriormente, debe alcanzar el consenso intersubjetivo.

Nuestra intención es mostrar cómo, desde la filosofía zubiriana, la racionalidad se articula en unidad estructural con los sentidos y madura intrínsecamente y en co-pertenencia a un sistema social determinado. Para ello trazamos la evolución de su pensamiento, que nos sirve de fulcro arquimédico para la revisión de la problemática. Esto implica mostrar los fundamentos intelectivos que permiten el acceso a lo real, o, como sostenemos, una pluralidad de vías a la realidad; imposibilitando así que un cierto tipo de saber se imponga o niegue por su estructura racional a otros (por ej. la racionalidad científica por sobre la poética, política, religiosa, teológica, etc.). Esto último lo ponemos en evidencia a partir de una contraposición de racionalidades (una racionalidad con trasfondo científico orientado a problemas religiosos y una de cuño religioso, stricto sensu), mostrando, de esta manera, las potencialidades de esta concepción para determinar la legitimidad y validez de los distintos tipos de saberes; lo que, en consecuencia, nos permite apreciar la diversidad de conocimientos sobre la realidad.

Esto admite, por consiguiente, que cada saber se constituya en un dominio de verdad con su propia fundamentación, $y$, asimismo, como portadores de una intrínseca "pretensión de validez". A modo de conclusión vemos las potenciales proyecciones que admite esta transformación en la concepción de la inteligencia hacia la sociología del conocimiento, el diálogo intercultural, $y$, por último, a partir de este diálogo entre saberes indagamos en las bases de una construcción interlógica.

\footnotetext{
${ }^{1}$ En otras palabras, una racionalidad monológica (Wilber 1996, 86, 150, 182-3), bajo el dominio total del método y de la "burocratización epistemológica" (Conill 1994, 134), desarraigada de la corporalidad (Conill 1995, 41-43) y, por ende, de los sentidos, con consecuencias graves para las ciencias sociales (Santos B. d. 2018b, 165-166).

${ }^{2}$ Veremos que, en definitiva, todo acceso a lo real no es la Verdad de la realidad, sino una "pretensión de verdad" confrontable con otras pretensiones desde un entendimiento intersubjetivo (Dussel 2010, 514).
}

Revista de Humanidades de Valparaíso, 2021, No 17, 231-250 
Razón y experiencia: contribuciones para una ampliación de la diversidad epistemológica

Fernando Lautaro Ramírez

\section{La evolución de la problemática entre inteligencia y realidad en el pensamiento de Zubiri}

Las revoluciones científicas producidas a principios del siglo XX a partir de los desarrollos de Einstein y de la mecánica cuántica son de decisiva importancia para Zubiri (1948). Estas hondas conmociones fueron tempranamente consideradas por él, principalmente, gracias a los desarrollos de Heisenberg. Allí observa cómo el paradigma moderno de la ciencia tal y como fue desarrollado ha llegado a una crisis irreversible; en efecto, la "nueva física" (Zubiri 1948, 266) ha hecho una ruptura con la concepción de Naturaleza y de física que tenía la modernidad (Zubiri 1948, 297)³. Todas estas revoluciones hacia el interior de la ciencia reflejan un genuino "problema de ontología de la Naturaleza" (Zubiri 1948, 322), para ello es necesario una revisión del vínculo de ciencia y verdad; en otras palabras: del lazo entre la inteligencia y la cosa.

La dificultad creciente por comprender el modo en que la inteligencia se vincula con las cosas, Zubiri la atribuirá, décadas más tarde, a la ausencia de una filosofía de la inteligencia y una metafísica (física trascendental, como a él le gusta decir). Justamente, es en una filosofía de la inteligencia donde se pueden definir con certeza cómo se estructuran internamente lo actos intelectivos, $y$, en tal sentido, se puede circunscribir adecuadamente a la racionalidad de la ciencia, pues, desde Kant, sobre todo, la filosofía se ha constituido como una crítica del conocimiento, una crítica de la episteme, esto es, en epistemología. En este sentido, advertiremos el equívoco que supone considerar que el conocimiento reposa sobre sí mismo. Para ello nos adentraremos en el modo estructural y formal de la inteligencia (Zubiri 1980, 11) anterior al logos y la razón (Zubiri 1980, 275-6).

El acto intelectivo a partir del cual tenemos una aprehensión de realidad no es algo desgajado del sentir. A lo largo de la historia de la filosofía se produce una gran dicotomía entre inteligencia y sensibilidad: esto comienza en Platón, pero llega hasta Hegel (Zubiri 1994, 328-9). En esta exclusión de la sensibilidad o del sentir se encuentra, solapadamente, una eliminación de la corporalidad misma (Zubiri 2001, 16) con grandes consecuencias, inclusive, para la teoría social.

A contramano de cualquier restricción de los sentidos, lo primero que debemos afirmar es que la inteligencia se encuentra en unidad formalmente estructural con el sentir, es decir, sentir e inteligir se hallan en activa unidad de apertura a la realidad (Zubiri 1980, 7981). La reducción de los sentidos a la visión como única presentación de lo real es parte del absurdo filosófico y científico que arrastra la historia de la filosofía. La identificación de lo visible con lo inteligible es una reducción, pues todas las cosas aprehendidas en impresión de realidad tienen su propia inteligibilidad (Zubiri 1980, 104).

A fin de arribar al modo de presentación de la realidad según los distintos sentidos, y de ahí al modo de operar de la razón, es preciso analizar cómo se da la apertura de

${ }^{3}$ Podemos encontrar con nitidez estos problemas en Heisenberg (1993, 5-41).

Revista de Humanidades de Valparaíso, 2021, No 17, 231-250

(c) (1) $(9)-1$ CC BY-NC-ND 
Razón y experiencia: contribuciones para una ampliación de la diversidad epistemológica

Fernando Lautaro Ramírez

realidad por parte del ser humano. Esto nos lleva a los análisis del acto intelectivo. En principio la inteligencia se encuentra en unidad estructural con el sentir, configurando una inteligencia-sentiente. De aquí que las cosas se presenten a la inteligencia como "impresión de realidad", es decir, como un sentir “en" la inteligencia. Inteligir es aprehender lo real como real, y sentir es aprehender lo real en impresión. Real significa aquí que los caracteres que tiene lo aprehendido en la aprehensión son "de suyo", "en propios"4. De esta manera las cosas se actualizan en la inteligencia, es decir, las cosas "están presentes desde su misma realidad". Esto se denomina: formalidad de realidad.

Esta última es una de las dimensiones de la aprehensión de realidad que se da en unidad con la "afección" y la "fuerza de imposición". Las cosas se dan a la inteligencia con un contenido y una formalidad de realidad. Esto constituye una habitud determinada, es decir, un modo de habérselas con las cosas. En el ser humano la formalidad presente en las cosas nos permite tratar con ellas como con una alteridad, pues las cosas "quedan" como siendo "otras", esto es lo que configura una habitud de alteridad, y es fuente de toda costumbre y hábito, en sentido estricto.

La visión, audición, olfato, gusto, sensibilidad laberíntica y vestibular, contacto-presión, calor, frío, dolor, kinestesia (abarcando el sentido muscular, tendinoso y articular), y la cenestesia o sensibilidad visceral, constituyen modos de presentación o de trato (habitud) de la realidad de forma distinta. Esto es lo distintivo; no las cualidades que nos ofrecen ni su contenido (Zubiri 1980, 100), es decir, no nos interesa tanto qué es: un color, un aroma, un paisaje, o un impulso inconsciente; sino el modo en que esto se hace presente en la inteligencia en unidad con los sentidos. Así, pues, por razones de espacio, utilidad y claridad, nuestro análisis se restringirá a algunos de estos sentidos que esclarecen los fines que se buscan elucidar.

La visión posibilita un trato con las cosas como "videncia". En la audición nuestro vínculo es "auscultando"; es la intelección como auscultación. En el gusto hay una aprehensión fruitiva; es decir, se está ante el fruir como intelección. En el tacto hay una aprehensión por "tanteo", se va a tientas entre las cosas. En el olfato tenemos una aprehensión de las cosas como "rastreo". Aquí se considera el rastro como la huella. En la kinestesia la intelección es una "tensión dinámica". Es la realidad misma como un "hacia" que nos tiene tensos.

Los distintos sentidos nos permiten inequívocamente un trato diverso con las cosas reales, sin embargo, puede pensarse que se encuentran de una manera compartimentada;

\footnotetext{
${ }^{4}$ Tomando un ejemplo de Diego Gracia: el calor, por ej., se aprehende como algo que es "de suyo" o "en propio" caliente, y no como algo que simplemente está calentando. [...] el calor se presenta en la aprehensión como siendo caliente "en propio", "de suyo", y por tanto como siendo "real" $(1986,105)$.
}

Revista de Humanidades de Valparaiso, 2021, No 17, 231-250

(c) (1)@९ $\mathrm{O}$ CC BY-NC-ND 
Razón y experiencia: contribuciones para una ampliación de la diversidad epistemológica

Fernando Lautaro Ramírez

por el contrario, se recubren unos a otros. Nos detendremos en el caso de la kinestesia, esto es, la aprehensión de la realidad en "hacia", a través de ella se dan modos de recubrimientos centrales para la posterior estructuración de la razón.

Recubriendo los demás sentidos, el "hacia" determina modos específicos de intelección. Así, recubriendo la presencia eidética de la realidad en la vista, determina en ésta un conato de visión hacia "dentro" [esto es, la reflexión]. Recubriendo la auscultación de la noticia, el "hacia" determina en ella una notificación a través de la noticia, hacia lo noticiable. Recubriendo todo lo aprehendido en todas sus demás formas, la intelección en "hacia" nos lanza a lo real allende lo aprehendido. (Zubiri $1980,108)$

El "hacia" como tensión dinámica nos revela varios aspectos estructurales de la inteligencia como habitud de alteridad. En primer lugar, nos muestra cómo las cosas se encuentran en respectividad unas con otras, es decir, hay una apertura trascendental de unas cosas "hacia" otras. Además, es decisiva en la búsqueda de lo real allende lo aprehendido, es decir, nos remite "hacia" fuera de la inteligencia.

En principio vale retener esto: la actualización de la realidad se da siempre en la inteligencia de modo inmediato, no hay un allende trans-intelectivo como consideraría un realismo ingenuo. Conocer qué son las cosas por fuera de la inteligencia es tarea propia de la razón sentiente, lo cual nos muestra el carácter medular que tiene el sentir en la estructuración misma de la razón, de la búsqueda de la realidad allende lo que está presente a la inteligencia. En este dominio es donde se encuentra el conocimiento en sentido general y la ciencia como una expresión particular de ella.

\subsection{Logos y habitud social}

Hemos definido una habitud de alteridad o modo de habérselas con las cosas donde los diferentes sentidos cumple un papel primordial, pues cada uno de ellos nos ha revelado modos peculiares de acceder a las cosas. Ahora bien, las cosas reales se encuentran constituyendo un "campo de realidad" por su constitutiva apertura trascendental de unas con otras. De este modo, ya no se inteligen sólo de manera individual e inmediata, sino unas cosas "entre" otras, y, por consiguiente, de manera mediata. Esto abre paso al dominio del logos. Desde él podremos averiguar, entonces, ya no como es algo "de suyo", sino cómo son las cosas "en realidad", es decir, como constituimos sentidos sobre ellas.

La habitud de alteridad si bien es parte del acto primordial de la inteligencia, no obstante, se encuentra modulada por los demás. Esto da paso a la habitud social en la cual se define el modo de habérselas con los demás, con las cosas y con uno mismo (González 2020, 147). Las habitudes sociales se definen en un campo de realidad, es decir los otros, las cosas y uno mismo se alojan en un ámbito que las incluye en su seno y posibilita ver-

Revista de Humanidades de Valparaíso, 2021, No 17, 231-250

(c) $(1)(9)$ CC BY-NC-ND 
Razón y experiencia: contribuciones para una ampliación de la diversidad epistemológica

Fernando Lautaro Ramírez

las. Todo campo es "medio de intelección", los medios pueden ser múltiples: sociales, religiosos, políticos, etc. ellos nos hacen ver las cosas de un modo diverso (Zubiri 1982, 75).

Así, pues, una realidad actualizada individualmente en sus notas (un bulto, por ej.), ahora debe aprehenderse "entre" otras realidades, según el tipo de medio en que nos encontremos es el modo en que la veamos y definamos, por último, qué sea ella "en realidad" (podemos seguir con un ej. simple: delimitamos si el bulto es un arbusto, un árbol o una farola). En este sentido, el tipo de aprehensión propia del logos es "dual", dado que una cosa se intelige desde otra (Zubiri 1982, 59).

Ahora, si el logos en el campo de realidad debe definir la significación que tienen las cosas dualmente, ello abre una pluralidad de sentidos posibles, dado que no hay un sentido restringido de lo concebible. Por ejemplo, podemos conceptuar lo que es un ser humano desde distintas direcciones: en la dirección de su figura animal, de su función psico-animal o como un ser creado a imagen y semejanza de Dios (Zubiri 1982, 105). Por esto todo campo es un "campo de libertad" (Zubiri 1982, 66). Cualquier univocidad de una afirmación o juicio constituye un "logificación de la inteligencia" (Zubiri 1982, 104).

Ahora bien, el logos puede aprehender las cosas en un campo de libertad, pero las habitudes sociales se encuentran fijadas, es decir, ya tienen un sentido definido que otorga permanencia y estabilidad al modo en que tratamos con las cosas. Pues ya siempre estamos inmersos en modos de "estar en la realidad" heredados (Zubiri 2006, 76) que han troquelado la manera en que entendemos unas cosas entre otras. En otras palabras, si bien toda significación de las cosas reales es una construcción, no obstante, los vínculos sociales tienden a delimitar un cierto criterio ideológico, un modo común de entender qué son las cosas "en realidad". Pues, socialmente construimos significados, valores y fines que dan sentido a las habitudes, es decir, permiten inteligir nuestras habitudes de determinada manera (González 1995, 75).

En este sentido, un conjunto de habitudes configura un sistema social, pues toda habitud está en relación de mutua determinación con otras, es una "habitud-de" (González 1995, 75). En su virtud, los diferentes sistemas sociales constituyen mundos histórico-culturales diferentes en cuyos horizontes tradicionales los modos de comprender lo que las cosas son en realidad se encuentran fijados y operan como presupuestos o incluso, podemos decir, bajo supuestos inaprensibles (Panikkar 2006).

Esto nos lleva a una reflexión ulterior. Si las habitudes sociales se encuentran fijadas, entonces podemos considerar que cada tradición cultural selecciona y jerarquiza la preponderancia de los sentidos en la apertura a la realidad, y, en función de ello, el logos delinea el sentido de las habitudes de un modo particular. De aquí que la centralidad de la visión y la audición como parte de la tradición cultural de occidente no es más que un orden intelectivo legitimado en un universo ideológico definido que ha derivado en

Revista de Humanidades de Valparaíso, 2021, No 17, 231-250

(c) $(1)(9)$ CC BY-NC-ND 
Razón y experiencia: contribuciones para una ampliación de la diversidad epistemológica

Fernando Lautaro Ramírez

saberes de suma relevancia como el científico, pero que, como toda función ideológica, puede operar un ocultamiento de la realidad, al pretender acotar el acceso a la realidad y las posibilidades que de ellas se derivan, como denuncia Santos (2018b, 166).

\subsection{Razón y experiencia}

Las habitudes sociales quedaron definidas por un conjunto de significaciones, valores, fines en torno a los demás, las cosas y uno mismo. De esta manera, la trama social posibilita un entendimiento sobre las cosas que ocurren en la vida cotidiana de los seres humanos, desde el modo de vestirse, de comer, de relacionarse con otros, hasta el modo de vincularse con la divinidad. Estos vínculos mediados por el logos tienen mayor o menor grado de opacidad, pues no siempre logran explicar satisfactoriamente todos estos aspectos de la vida social. El peligro radica en tratar con la apariencia de las cosas (Zubiri 1982,303 ss) y no con un sentido esclarecido de las mismas. Por ello, para lograr una mayor trasparencia de estos fenómenos, que permitan mayor amplitud y profundidad en los vínculos, es necesaria la intervención de la razón.

En este sentido, las cosas campales al estar sumidas en cierta opacidad nos "dan qué pensar" y nos "remiten a lo allende" (Zubiri 1983, 41), en busca del fundamento de las cosas. Supongamos un caso muy simple: si nuestra apertura a la realidad es vidente, esto me indica que al abrir los ojos intelijo algo con ciertas notas (aprehensión primordial), pero luego ese algo lo aprehendo "entre" otras cosas y queda determinado como luz y no como fuego, por ej. Ahora bien, el proceso no concluye ahí, la razón teórica puede encontrar insuficiente o insatisfactorio el sentido que ha quedado fijado en el logos en torno a este fenómeno, por lo que se empeña en averiguar qué es eso en profundidad. Es una marcha que buscará lo que las cosas reales "pueden ser" en el fondo: nuestra luz podrá ser una onda electromagnética o un fotón (Zubiri 1983, 12).

Este buscar en el fondo lo que son las cosas reales no es privativo de la razón teórica, sino que puede ser también lo que forja una novela o una poesía, como realidad en ficción, sin cambiar un ápice de la esencia de la intelección (Zubiri 1983, 43). Este aspecto es decisivo, pues la razón como tal es una búsqueda que realiza la inteligencia en todos los órdenes del pensar, de aquí que la realidad personal o de los demás puedan ser pensadas poéticamente, como teóricamente; literariamente, como religiosamente. En todos los casos tenemos conocimiento sobre la realidad profunda de las cosas y podemos dar un fundamento diferente de las mismas (Zubiri 1983, 161ss).

Las habitudes sociales delimitan distintos tipos de habitudes intelectivas de lanzamiento o racionalidades, esto es, diferentes formas de habérnosla con lo allende la inteligencia. En consecuencia, el modo de ordenar los vínculos sociales, el trato y sentido que le damos 
Razón y experiencia: contribuciones para una ampliación de la diversidad epistemológica

Fernando Lautaro Ramírez

a las cosas, e incluso con lo divino, puede encontrar diversos tipos de fundamentación, esto dependerá de la mentalidad predominante de una cultura (Zubiri 1983, 151), caso que analizaremos más adelante.

Supongamos que la mentalidad o habitud dominante es científico-teórica, entonces si nos disponemos a buscar el fundamento de un color determinado es necesario tener una vía de acceso a la misma, es decir, un método, que se adecue a dicha mentalidad: en el caso de la ciencia, el método científico constituye un tipo particular de vía de acceso a esa realidad profunda (Zubiri 1983, 172). El logos que define las diferentes habitudes sociales se constituye en el "sistema de referencias" desde el cual podemos escrutar la realidad en su fundamento. Este sistema de referencias nos permite esbozar posibilidades de lo que las cosas puedan ser en su fundamento. Al insertar alguna de estas posibilidades en la realidad, lo que tenemos es justamente una experiencia.

La experiencia se constituye como una "probación física de realidad" (Zubiri 1983, 227). Nos abrimos al mundo discerniendo entre las posibilidades que hemos esbozado a fin de determinar cuál de ellas se inserta correctamente en el mundo. Esta probación física es una libre creación, lo cual revela el carácter creativo del proceso intelectivo. Esta, asimismo, se encuentra modalizada debido a la diversidad de sistemas de referencias posibles, y los esbozos de posibilidades concomitantes con ellos. Este sistema está constituido por el campo sentiente. Como vimos, el campo configura un universo categorial, simbólico, metafórico, en función del cual establecemos posibilidades, es decir, en función de lo que las cosas son en realidad estipulamos lo que "podrían ser" en la realidad.

La diversidad de experiencias implica diversidad de métodos, que es posible gracia a la diversidad interna que constituye el sistema de referencia. Entre los modos de experiencia fundamentales que encontramos en el conocimiento están aquellas que no presentan ninguna dificultad para la razón, por lo que resultan obvias. Hay otras de mayor dificultad, como la "compenetración". Esta es una experiencia que consiste en el intento de instalarse el experienciador en lo experiencial a fin de experimentarlo desde su propia interioridad. Es decir, intentamos ver desde dentro, experienciar desde dentro, para ello la compenetración con una persona, con un ser biológico, por ej., nos abre esa posibilidad (Zubiri 1983, 249-51). También está la “conformación”, esto es, la experienciación de la propia realidad, de mi realidad como persona.

Un caso particular es el experimento, es un modo de probación física de la realidad campal que "consiste en forzarla a mostrar su índole profunda ante el experienciador" (Zubiri 1983, 248). Es decir, se produce una intelección manipulada de lo real, donde la manipulación misma es un modo de intelección. Los conceptos que se elaboran son ya conceptos experimentales, o "experimentos formalmente conceptuales" (Zubiri 1983, 248). Las experimentaciones científicas sobre la luz (o el color) nos lleva a la experiencia de un fotón (o una onda electromagnética). De este modo se da una intelección manejada de lo real, no una intelección de lo manejado.

Revista de Humanidades de Valparaíso, 2021, No 17, 231-250

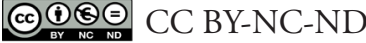


Estas diversas experiencias son el desenlace del proceso de intelección racional, cuyo término es el encuentro con la realidad específica, es decir, buscamos que se cumpla el esbozo de posibilidad. El "cumplimiento [de lo esbozado] tiene por esencia propia la "verificación'”. Verificación es un verum facere (Zubiri 1983, 264). Esta verificación consiste en que la realidad confirme (fundamente) lo que entendemos acerca de ella, a partir de la adecuación de nuestros conceptos. Esta progresiva verificación Zubiri la denomina "La dialéctica de la adecuación" (Zubiri 1983, 271-2). En otras palabras, lo que intentamos llevar a cabo es una aproximación lo más certera posible hacia la realidad en cuanto realidad. Para ello adoptamos diversas vías ya sea teórico-conceptuales como encontramos en la ciencia, en las ficciones literarias, o en el discurso religioso, etcétera.

\section{Implicaciones derivadas: aspectos significativos de la actividad racional}

Hemos podido apreciar que razón y experiencia se constituyen en un diálogo laborioso, sesudo y sin garantías desde sus propios parámetros lógicos con la realidad. Esta danza de la razón sentiente nos recuerda que todo mapa cognitivo (razón teórica, poética, filosófica, religiosa) conjura de un modo determinado lo que son las cosas en la realidad, pero sin poder arrebatar una esencia definitiva de la misma, pues siempre nos hallamos en "marcha 'hacia lo otro"" (Zubiri 1983, 68). Así, pues, esta alteridad radical de la realidad la encontramos como una signatura lapidaria en el pórtico de la razón.

Este carácter de alteridad puede resultar inquietante para la tiranía de "lo mismo" (Dussel 1995, 109-120), pero es el fundamento de la novedad, de la experiencia, y de la crítica misma de aquello que busca tenazmente reducir lo real a ciertos criterios lógicos. Esto mismo es designado por Morin como racionalización (1999, 7; 2000, 19), es decir, una razón cuyo ensamblaje lógico pretende apresar la realidad dentro de su sistema.

Ahora bien, esta alteridad de la realidad rompe con toda pretensión totalizante, este es el gran equívoco kantiano: considerar que cierto sistema de verdades racionales (científicas, en este caso) unidas por respectividad constituyen la totalidad de las verdades racionales; esto lleva al error de considerar que hemos podido clausurar el universo de verdades sobre la realidad (Zubiri 1983, 290). Esto nos permite abrigar inequívocamente que el multum in parvo borgeano es contrario a las posibilidades mismas del saber científico. Sin embargo, Borges magistralmente nos evoca desde su razón literaria lo que podría ser una realidad cuyos misterios han sido por completo develados; es decir, desde esta perspectiva podemos apreciar lo que esto significaría: es decir, la muerte prematura de la experiencia, de toda novedad y de la posibilidad de enriquecimiento de las formas de vida o habitudes sociales.

Esto nos deja en claro que, al no haber verdades racionales definitivas, la razón solo puede albergar una "pretensión de verdad", es decir, ser una vía de acceso a lo real con garantías parciales, no totales, pues siempre rige como trasfondo el principio de incer- 
Razón y experiencia: contribuciones para una ampliación de la diversidad epistemológica

Fernando Lautaro Ramírez

tidumbre racional (Morin 1999, 43). ¿Qué distingue a la ciencia del resto de saberes? $\mathrm{Su}$ capacidad de lograr una mayor adecuación de sus esbozos de posibilidades. Es decir, posee una amplia capacidad de verificación de sus afirmaciones teóricas, por lo que es posible suscribir a la idea de que en ella hay un mayor carácter racional que en otros discursos racionales. Por ejemplo: si afirmamos teóricamente que la luz en el fondo es un fotón, y la experimentación lo verifica, entonces nos encontramos frente un cumplimiento de nuestro esbozo teórico. Esto posibilita cierto "progreso" racional, aun cuando: "nunca sabremos cuál es la única o total razón de nada, porque la encontrada puede ser sustituida por otra o subsumida por ella (Zubiri)_-" (Ellacuría 1991, 98).

En el ámbito de las ciencias sociales la cuestión es similar, más no del todo homologable. En ella encontramos esbozos teóricos en torno a determinados hechos sociales que podemos verificar en su fundamento, como por ej., el modo en que Marx demuestra, frente al conjunto de economistas de su época, que la plusvalía es la causa de la constante revalorización del capital (González 1995, 84-5). Esta fundamentación, no obstante, está sujeta a una continua verificación. Un aspecto preponderante es que el hecho social, aún con sus particularidades, pues responde a un conjunto de conceptos previos, continúa siendo un fenómeno observable (Zubiri 1983, 184-5). En este sentido, el discurso de las ciencias sociales se constituye desde la legitimación que tienen los fenómenos observables, como por su capacidad de verificación y, por tanto, de objetividad; en contraste con otros. En el apartado siguiente veremos las dificultades de esto para posibilitar un diálogo con otras racionalidades.

Recapitulando podemos decir que los diferentes sistemas sociales dan prioridad ha determinado tipos de aperturas intelectivas a la realidad, en este sentido, la visión y la audición han sido decisivas para la tradición occidental. Estas diversas aperturas coagulan modos precisos de entender las cosas fijando así determinadas habitudes sociales. Así, pues, la razón teórica - theorein, de ahí visión - que ha definido a las ciencias en general, como sospecha Santos $(2018 b, 166)$, es un precipitado natural de un sistema social como el occidental. Ahora bien, junto con la razón teórica convive una multiplicidad de modos de lanzamiento a lo real como pueden ser poéticos, políticos, religiosos, etc. Ocultar el carácter legítimo de fundamentación de la realidad de estos saberes alternativos constituye un cerco ideológico que, desde esta concepción racional, queda claramente revertido.

\section{Hacia una diversidad epistemológica, ergo: hacia una diversidad del mundo}

En los últimos puntos nos hemos centrado en la propuesta de Zubiri, sus implicancias en una comprensión renovada de la racionalidad, junto a las potencialidades que le son inherentes para dar una explicación alternativa a los desafíos presentados por la raciona-

Revista de Humanidades de Valparaíso, 2021, No 17, 231-250

(c) $(1) \Theta(9)$ CC BY-NC-ND 
Razón y experiencia: contribuciones para una ampliación de la diversidad epistemológica

Fernando Lautaro Ramírez

lidad científica, fundamentalmente. En este sentido nos proponemos indagar en las virtualidades de esta racionalidad para poner en evidencia la diversidad epistemológica del mundo ${ }^{5}$ poniendo el foco en la validez intrínseca de los saberes.

Para ello nos adentraremos en otro tipo de saber: el religioso, pues encontramos en este la posibilidad de explicitar de modo óptimo las virtualidades enunciadas. Además, nuestro interés se debe a que es un saber que ha cobrado una mayor relevancia en tanto elemento constitutivo de la vida pública, sumado a que es un articulador e inspirador de experiencias contrahegemónicas (Santos 2014, 25). En virtud de esto, es perentorio cuestionar cierto discurso de las ciencias sociales que considera que la religión implica un sacrificio del intelecto ${ }^{6}$, es decir, la declaran abiertamente irracional, y por ende refuerzan la centralidad del saber científico.

Pues bien, a fin de abordar en su riqueza las posibilidades contenidas en la razón sentiente de Zubiri abordaremos la cuestión religiosa desde un encuentro intercultural que cuenta Raimon Panikkar sobre un pastor protestante que en Vrindâvana le decía irónicamente a un hindú:

Jesús de Nazaret ha existido, conocemos su historia, sus hechos, su vida, milagros y demás; es una realidad innegable que sigue durando después de veinte siglos. En cambio vuestro Krishna es una leyenda, y, encima, como tal no es muy edificante... es un mito; no ha existido, no es algo real. (Prieto 2005, 67)

Y agrega que, frente a esto, el "vaishnava hindú le contesta sonriendo que es verdad, que Jesús es un gran hombre histórico, como Napoleón... pero nada más. En cambio, el Krishna de su corazón y de su fe es lo verdaderamente real, lo que le mueve" (Prieto 2005, 67).

Esta anécdota retrata ostensiblemente dos sistemas sociales dicotómicos: Oriente/Occidente, por tener horizontes de inteligibilidad culturalmente contrapuestos. Por un lado, el de la religión cristiana donde su experiencia de la realidad es el hecho histórico que constituye la figura de Jesús de Nazaret. Por el otro lado, la realidad Krishna considerada un mito, al no ser histórica, y por tanto, como irreal. Las diferencias culturales y religiosas que aquí se ponen en juego tienen que ver con el grado de realidad que adquiere aquello que es histórico y aquello que no, como afirma Panikkar (2007, 115-20). En este sentido, examinaremos cómo nuestra inteligibilidad del mundo depende del sistema de referencia (universo conceptual o simbólico) que esté en juego.

\footnotetext{
${ }^{5}$ Consideraremos epistemológica a todas las racionalidades, porque en todos los casos se hace una intelección del fundamento de la realidad; la ciencia, en tal sentido, es uno de los modos posibles de dicha aprehensión.

${ }^{6}$ En la obra de Weber $(1979,228)$ encontramos justamente una aproximación de este tipo. Para una aproximación a sus causas cfr. Wilber $(2007,313 \mathrm{ss})$.
}

Revista de Humanidades de Valparaíso, 2021, No 17, 231-250 
Razón y experiencia: contribuciones para una ampliación de la diversidad epistemológica

Fernando Lautaro Ramírez

El hecho, en términos generales, es un positum, aquello que consideramos presente como observable, pero debe ser observable para cualquiera. En este sentido, sostuvimos que el hecho científico-social (religioso, en este caso) está referido a un sistema de conceptos previos. En la tradición occidental cristiana el decurso histórico, los monumentos como precipitados históricos, los archivos históricos, los textos históricos, los registros arqueológicos como huellas de los hombres y mujeres del pasado, constituyen hechos científicamente reales. Esto inevitablemente delimita lo que es considerado real en dicha racionalidad. Así, pues, si nuestro sistema de referencia toma lo que está presente de modo observable, ya sea histórico o no, como el único esbozo de posibilidad, entonces, nuestra experiencia de ello es sinónimo de objetividad, y, por tanto, de afirmación racional.

Si tomamos el caso de "Jesús de Nazaret" podemos considerar que al constatar en los documentos históricos y los registros arqueológicos, estamos efectivamente frente a un hecho histórico confirmado, por consiguiente nos encontramos, para una mentalidad occidental, ante un discurso claramente racional, o al menos razonable. Del otro lado, en cambio, queda la irracionalidad, el sin sentido, por ser inverificable bajo estos criterios. Este punto de vista positivista es el que mejor encarna la razón metonímica, como declara Santos $(2006,103)$, su operación consiste en reducir la realidad a lo existente según sus parámetros lógico-analíticos, a saber: lo observable (Santos 2017, 219). Podemos decir con Panikkar (2006) que esta es una "epistemología del cazador", por ser una actividad dirigida a la caza de información. Por consiguiente, corre el peligro de escindirse de la ontología, al restringirse a la verificación de datos o hechos y, por tanto, atar sus afirmaciones solo a criterios objetivos (Panikkar 2006, 52ss). Esta epistemología nos lleva a la arena de la lucha y confrontación y no al ágora: lugar del encuentro entre dialogantes (Panikkar 2006, 53).

Para ampliar el registro epistémico y social y restituir al ágora como lugar de encuentro, es necesario una revisión de la reducción de lo real ha hecho histórico, ya que no hace justicia a la realidad al absolutizarse como posición epistémica. En este sentido, ¿cómo se da la verdad de este tipo de conocimiento ahistórico, es decir, que no está sujeto a una consideración historicista, justamente porque no responde a un devenir temporal, ni a un legado en sus diversos precipitados históricos? Nuestro análisis nos llevó por una dimensión de realidad que tiene que ver con la formalidad del "de suyo". Los modos en que la realidad se presenta no pueden ser reducidos a la visión, esto es un absurdo incluso filosófico y científico (Zubiri 1980, 104); asimismo, esto hace de la fe (o saber religioso), al no ser visible, algo irracional, pues hay una identidad entre saber y ver (Zubiri 1985, 224-5) que fuerza a toda verdad religiosa a una dimensión estrictamente observable.

Ahora bien, la realidad divina, Krishna en este caso, parten de otros modos de presentación de la realidad. La audición, habíamos dicho, nos presenta la realidad como noticia, en el gusto se da una aprehensión fruitiva; en la dimensión kinestésica, como hemos visto, se nos da la realidad "en hacia", la realidad nos tiene tensos hacia ella, es tensión diná- 
Razón y experiencia: contribuciones para una ampliación de la diversidad epistemológica

Fernando Lautaro Ramírez

mica. Afirma Zubiri: "toda fe envuelve una intelección de tipo no visual, pero sí de tipo auditivo, en noticia, y "en hacia"” $(1985,235)$. Para ilustrar la experiencia de la divinidad esta última dimensión es fundamental?

El ser humano constituye su propia esencia habitudinal en apertura a las cosas reales. Estas cosas ejercen un poder, es el poder de lo real, que lo mantiene religado a la realidad. La realidad divina, en este sentido, no está allí visiblemente en las cosas, en los documentos, sino que todas las cosas reales tienen algo que las excede, que las hace ambivalentes, de allí el carácter enigmático de la realidad. Por el enigma que envuelve a la realidad, sumado al poder que tiene, nos vemos llevados hacia él (Zubiri 1985, 229). Es decir, por la presencia de lo enigmático nos hallamos lanzados "hacia" su raíz, a saber: una búsqueda de la raíz misma que envuelve lo enigmático; de aquí que la intelección propia de lo enigmático es "en hacia", es estar direccionados hacia ello. Ahora bien, ese hacia al que nos hallamos lanzados no tiene un término determinado, sino que nos tiene lanzados hacia su fundamento "en" las cosas mismas. La inteligencia en este sentido "prueba" (probación física, experiencia) que ese "algo", en las cosas mismas, que es fundamento del poder de lo real, es Dios.

Este punto es decisivo. La razón determina en este caso que Dios es el fundamento de este esbozo, lo cual se podría objetar que esa posibilidad no agota otras posibilidades (psicológicas, sociológicas, históricas). En efecto, la posibilidad de que el fundamento de lo enigmático sea Dios, no es exclusiva, ni excluyente, pero justamente por ello ninguna otra posibilidad puede pretender tener una respuesta exclusiva sobre el enigma de la realidad (González 2011, 511).

Así, pues, el ser humano (desde cualquier perspectiva religiosa) esboza la posibilidad de que aquella realidad direccional, que es fundamento de lo enigmático, es Dios; esto es, Dios como fundamento del poder de lo real en la religación. Asimismo, Dios como realidad-fundamento acontece "fundamentándome" desde el fondo de la realidad (Zubiri 1985, 229-31). De aquí que el vaishnava hindú diga que el Krishna de su corazón y su fe (aun cuando no es visible, documental e históricamente, al menos) es lo verdaderamente real, lo que lo mueve; pues lo "conoce" y acontece en su vida fundamentándolo8.

A partir de esta ampliación del registro intelectivo abrimos una puerta a otras dimensiones de la realidad que no implica "ver" una realidad-objeto como puede ser un documento. De esta manera, podemos mostrar la "pretensión de verdad" que encierran estas

\footnotetext{
${ }^{7}$ Los análisis de Zubiri sobre la religación ponen en evidencia que esta constituye un hecho universal, que es anterior a todo sentido religioso. Por esto puede comprender a las distintas plasmaciones religiosas como diferentes variantes de aquella (González 2011, 506).

${ }^{8}$ R. Panikkar afirma que las Upanișad constituyen un ingente esfuerzo de la mente humana por descifrar el enigma del mundo y su conexión con el Origen último (Panikkar 2005, 87-8). Esto permite mostrar el esfuerzo racional de indagar desde otro sistema de referencia en lo enigmático de la realidad y el fundamento del mismo.
}

Revista de Humanidades de Valparaíso, 2021, No 17, 231-250 
Razón y experiencia: contribuciones para una ampliación de la diversidad epistemológica

Fernando Lautaro Ramírez

afirmaciones, ya que posee fundamentos racionales aun cuando, desde ciertos posicionamientos científico social, implica una abdicación de la razón. La racionalidad de su experiencia se funda en ser una vía de compenetración de la propia realidad humana con la realidad-fundamento. La verificación de su acontecimiento, al igual que la del acceso poético a la realidad, parte de una experiencia de compenetración de la propia realidad con la de Dios, Krishna en este caso, como remarca Panikkar (2005, 324-5).

Dicha compenetración no prescribe una verdad objetivadora, o sea una adecuación unívoca, que pretende el dominio de la realidad; por el contrario, su vínculo es simbólico-ritual (Picotti 1990, 20ss), donde la religación con la realidad y con Dios como fundamento de la misma acontece de múltiples maneras, debido a la condición ambigua de la realidad que provoca un juego de adecuación-inadecuación, donde todo vínculo con el fundamento se da como probación indicatoria más que como término inequívoco (Picotti 1990, 65-6).

Una experiencia semejante a esta la podemos ver en el modo de articulación de la sabiduría popular latinoamericana (Scannone 2010; 2011); allí, precisamente, la experiencia de Dios (alteridad vertical) y de los otros (alteridad horizontal) parte de una racionalidad sapiencial: esto es, del saber que "sabe" (sapere: sabor, de ahí saber) y no tanto de la intuición intelectual que ve, ni del oír creyente. En términos zubirianos esta experiencia de la realidad parte de una aprehensión fruitiva, es decir, todo vínculo de religación con la realidad se da en una tensión dinámica "hacia" esta, pero con un carácter fruitivo, donde lo verificado también tiene un carácter simbólico por su riqueza y excedencia (Scannone 2010, 59), o sea, la realidad nos da múltiples sentidos de sí misma, por ser también una racionalidad que se entrevera en un juego de adecuación- inadecuación. De aquí también surge una actitud de religación con la realidad, donde la experiencia no queda recluida en la actitud objetivadora del saber científico.

\section{A modo de conclusión: diálogo de racionalidades e interlogos}

Nuestra elucidación teórica ha seguido el hilo conductor de la reflexión zubiriana. Sus tempranas disquisiciones sobre la situación intelectual científica de Europa occidental le advertían sobre los riesgos inherentes de un positivismo y pragmatismo en extremo que nosotros caracterizamos con el cuento borgeano, y cuyas consecuencias más ostensibles eran la reducción del saber y por tanto de la experiencia, y, ulteriormente, de lo que es considerado como realidad. A partir de esto nos propusimos seguir la trama analítica de la filosofía de la inteligencia de este autor, lo que nos permitió concluir que la actividad o forma de conocimiento teórica que caracteriza a la ciencia es una entre otras posibles, por ej.: poético, política, religiosa, etc., además de que ninguna de ellas puede agotar la totalidad de la realidad, sino ser simples aproximaciones a la realidad en su fundamento.

Revista de Humanidades de Valparaíso, 2021, No 17, 231-250

(c) $(9)(9)$ CC BY-NC-ND 
Razón y experiencia: contribuciones para una ampliación de la diversidad epistemológica

Fernando Lautaro Ramírez

Esto fue puesto en evidencia en la contraposición entre el saber científico-histórico y el saber religioso. Este ejemplo resultó paradigmático porque nos enseña dos cosas centrales: primero, nos permite entrever que el saber no puede quedar circunscripto a la mera visión, sino que es necesario una consideración de la amplia gama de modos en que se nos presenta la realidad, es decir, desde la visión y la audición, hasta el gusto, el olfato, la kinestesia, entre otros. En otras palabras, es imperioso fundamentar el saber desde una razón sentiente en el amplio sentido del término. En segundo lugar, nos mostró cómo las diferentes aperturas a la "realidad fundamental" que se pueden llevar a cabo desde esta perspectiva de conocimiento encierran una legítima "pretensión de verdad"; en consecuencia, no podemos considerar que una cultura determinada familiarizada con una vía de acceso a lo real, como es la teórica-conceptual, logre una completud del saber. Por ello, ningún saber puede ser descartado como inválido de antemano. Esto constituye, a nuestro entender, los fundamentos filosóficos, aunque incipientes, de unas epistemologías postabismales (Santos 2018a, 28-9).

Esto último que hemos apuntado refiere a las directas virtualidades que tienen estas reflexiones para otras disciplinas, fundamentalmente, para una sociología del conocimiento como son las Epistemologías del Sur promovidas por Boaventura de Sousa Santos. Para este autor, la racionalidad adolece de indolencia (Santos 2003, 44) al efectuar una reducción de la experiencia social, debido a la imposibilidad de superar los márgenes que la ciencia le ha trazado al conocimiento. En otras palabras, Santos observa que en la razón cientificista redujo la multiplicidad de mundos existentes, comprensiones del mundo, que había en Oriente: terrenos y ultraterrenos, al mundo terreno. La secularización y la laicización son ejemplos de ello (Santos 2009, 105).

En rigor, dicha racionalidad tiene una comprensión de sí misma no sólo parcial y limitada, sino selectiva (Santos 2009, 104-5), es decir, en su encierro epistémico, ella cree poder abrazar en un multum in parvo (por seguir la metáfora propuesta) la totalidad de la realidad, creando una ficción metonímica cuya consecuencia directa fue la constitución de una cesura abismal con todos aquellos saberes que no se ajustan a sus requerimientos. De aquí nacen las grandes dicotomías: conocimiento científico/conocimiento tradicional; cultura/naturaleza; Norte/Sur; Oriente/Occidente, etcétera (Santos 2009, 103-4).

Esto lleva a un punto más preocupante: la imposibilidad de considerar dichos saberes independientemente de la totalidad trazada por el saber occidental, es decir, las dicotomías esbozadas más arriba no establecen una relación libre y orgánica entre ellas; sino que se da una suerte de heteronomía por parte de una de ellas que determina y somete a la otra: el conocimiento científico subyuga el conocimiento tradicional; el Norte sobre el Sur; etcétera. En virtud de ello se provoca un desperdicio y pobreza de experiencia que conlleva un achicamiento significativo del horizonte (paradigma societal y epistemológico) del que emergen las alternativas históricas emancipadoras para las crisis a las que nos lleva el sistema-mundo moderno occidental (Santos 2018a).

Revista de Humanidades de Valparaíso, 2021, No 17, 231-250

(c) $(1)(9)$ CC BY-NC-ND 
Pues bien, la concepción de razón sentiente al permitir que nos desmarquemos del canon cientificista que se ha instaurado como perspectiva monológica y como cesura abismal, nos abre la posibilidad de revisar las jerarquías y asimetrías de los saberes, promoviendo una convivencia de sus diferentes lógicas, o incluso pensar en un diálogo intercultural genuino, es decir, restituir el lugar del ágora donde las alteridades histórico-culturales tienen visibilidad y pueden entablar un diálogo entre ellas, viabilizando una interpenetración de sus distintas lógicas. Esto es posible porque todas las posiciones tienen validez relativa, al configurarse como vías posibles a la realidad, por lo que nos permite pensar en un entrecruzamiento de horizontes desde el cual caminar. O, como lo piensa Dina Picotti, es necesario (y posible, diríamos nosotros) desplazar el logos unívoco desde el cual se lee universalmente la realidad, y dar lugar al diálogo de alteridades, construyendo entre ellas un interlogos (Picotti 1990, 43).

\section{Referencias bibliográficas}

Borges, J. L. (1974). Obras Completas. Buenos Aires: Emecé.

Conill, J. (1994). Hermenéutica antropológica de la razón experiencial. En D. B. Fernández et al. (Ed.), Discurso y realidad. En debate con K. - O. Apel, pp. 131-143. Madrid: Trotta.

Conill, J. (1995). Zubiri en el crepúsculo de la metafísica. En D. G. et al (Ed.), Del sentido a la realidad. Estudios sobre la filosofía de Zubiri, pp. 33-50. Madrid: Trotta.

Heisenberg, W. (1993). La imagen de la naturaleza en la física actual. Barcelona: Planeta-De Agostini.

Dussel, E. (1995). Introducción a la filosofía de la liberación. Bogotá: Nueva América.

Dussel, E. (2010). Deconstrucción del concepto de "tolerancia" (De la tolerancia a la solidaridad). En M. Giusti, Tolerancia: El estado de la cuestión, pp. 513-519. Lima: Fondo Editorial Pontificia Universidad Católica del Perú.

Ellacuría, I. (1991). Veinte años de historia en el Salvador (1969-1989): escritos políticos I. San Salvador: UCA Editores.

González, A. (1995). Hacia una fundamentación de las Ciencias Sociales. En A. González, Para una filosofía liberadora, pp. 65-96. San Salvador.

González, A. (2011). Aproximación a la filosofía zubiriana de la religión. En J. A. Nicolás, Guía Comares de Zubiri, pp. 503-518. Granada: Comares.

González, A. (2020). Un solo mundo. La relevancia de Zubiri para la teoría social. Obtenido de Universidad Centroamericana José Simeón Cañas: http://www.uca.edu.sv/ facultad/chn/c1170/agtdind.html. Consulta: 21/08/2020

Gracia, D. (1986). Voluntad de verdad. Para leer a Zubiri. Barcelona: Labor.

Revista de Humanidades de Valparaíso, 2021, No 17, 231-250

(c) (1) @ $९$ CC BY-NC-ND 
Razón y experiencia: contribuciones para una ampliación de la diversidad epistemológica

Fernando Lautaro Ramírez

Heisenberg, W. (1993). La imagen de la naturaleza en la física actual. Barcelona: Planeta-De Agostini.

Morin, E. (1999). Los siete saberes necesarios para la educación del futuro. París: UNES$\mathrm{CO}$.

Morin, E. (2000). Introducción al pensamiento complejo. Madrid: Gedisa.

Panikkar, R. (2005). Espiritualidad hindú. Sanāthana Dharma. Barcelona: Kairós.

Panikkar, R. (2006). Paz e interculturalidad. Una reflexión filosófica. Barcelona: Herder.

Panikkar, R. (2007). Mito, Fe y Hermenéutica. Barcelona: Herder.

Picotti, D. (1990). El descubrimiento de América y la otredad de las culturas. Buenos Aires: RundiNuskín.

Prieto, V. P. (2005). Raimon Panikkar: el pensamiento cristiano es trinitario, simbólico y relacional. Iglesia Viva: Revista de Pensamiento Cristiano, 223, 63-82.

Roig, A. A. (2017). El cuento del cuento. En A. Arpini y C. Jalif de Bertranou, Diversidad e integración en nuestra América. Volumen III: La construcción de la unidad latinoamericana: alteridad, reconocimiento, liberación (1960-2010), pp. 171-174. Buenos Aires: Biblos.

Santos, B. d. (2003). Crítica de la razón indolente: contra el desperdicio de la experiencia. Bilbao: Desclée de Brouwer.

Santos, B. d. (2006). Conocer desde el Sur. Para una cultura política emancipatoria. Lima: Fondo Editorial de la Facultad de Ciencias Sociales UNMSM.

Santos, B. d. (2009). Una epistemología del sur: la reinvención del conocimiento y la emancipación social. México: Siglo XXI; CLACSO.

Santos, B. d. (2014). Si Dios fuese un activista de los derechos humanos. Madrid: Trotta.

Santos, B. d. (2017). Justicia entre saberes: Epistemologías del Sur contra el epistemicidio. Madrid: Morata.

Santos, B. d. (2018a). Introducción a las Epistemologías del Sur. En M. P. Meneses y K. Bidaseca, Epistemologías del Sur - Epistemologias do Sul, pp. 25-62. Ciudad Autónoma de Buenos Aires; Coimbra: CLACSO, CES.

Santos, B. d. (2018b). The end of the cognitive empire. The coming of age of the Epistemologies of the South. Durham and London: Duke University Press.

Scannone, J. C. (2010). Nuevo punto de partida de la filosofía latinoamericana. Buenos Aires: Docencia.

Scannone, J. C. (2011). Teología de la liberación y praxis popular. Buenos Aires: Docencia.

Revista de Humanidades de Valparaíso, 2021, No 17, 231-250

(c) (1) @९ $\mathrm{CC}$ BY-NC-ND 
Razón y experiencia: contribuciones para una ampliación de la diversidad epistemológica

Fernando Lautaro Ramírez

Weber, M. (1979). El político y el científico. Madrid: Alianza.

Wilber, K. (1996). Sexo, Ecología, Espiritualidad: El alma de la evolución. Madrid: GAIA.

Wilber, K. (2007). Espiritualidad integral. El nuevo papel de la religión en el mundo actual. Barcelona: Kairós.

Zubiri, X. (1948). Naturaleza, Historia y Dios. Buenos Aires: Poblet.

Zubiri, X. (1980). Inteligencia-sentiente: Inteligencia y realidad. Madrid: Alianza editorial.

Zubiri, X. (1982). Inteligencia sentiente: Inteligencia y logos. Madrid: Alianza editorial.

Zubiri, X. (1983). Inteligencia sentiente: Inteligencia y razón. Madrid: Alianza Editorial.

Zubiri, X. (1985). El hombre y Dios. Madrid: Alianza.

Zubiri, X. (1994). Los problemas fundamentales de la metafísica occidental. Madrid: Alianza.

Zubiri, X. (2001). Sobre la realidad. Madrid: Alianza.

Zubiri, X. (2006). Tres dimensiones del ser humano: individual, social e histórica. Madrid: Alianza.

Revista de Humanidades de Valparaíso, 2021, No 17, 231-250

(c) (1) $\circledast 9$ CC BY-NC-ND 